\title{
Controle da ferrugem das folhas do capim-limão [Cymbopogon citratus (DC.) Stapf] com produtos naturais
}

\author{
LORENZETTI, E.R. ${ }^{1 *}$; CONCEIÇÃO, D.M. ${ }^{1}$; SACRAMENTO, L.V.S. ${ }^{2}$; FURTADO, E.L. ${ }^{1}$ \\ ${ }^{1}$ UNESP, FCA, Departamento de Produção Vegetal, Caixa Postal 237, CEP: 18610-307, Botucatu-Brasil ${ }^{2}$ UNESP, \\ FCF, Departamento de Princípios Ativos Naturais e Toxicologia, Rodovia Araraquara - Jaú Km 1, CEP: 14801-902, \\ Araraquara-Brasil *elorenzetti@gmail.com
}

\begin{abstract}
RESUMO: Cymbopogon citratus (DC.) Stapf é uma planta medicinal pertencente a família Poaceae, perene, importante para a indústria farmacêutica e alimentícia devido ao óleo essencial que produz. Um problema limitante para a produção comercial é a ferrugem, doença cujo agente etiológico é o fungo Puccinia nakanishikii Dietel. O presente trabalho objetivou avaliar a ação de produtos naturais no controle da doença in vitro e in vivo. Para os testes in vitro, empregaram-se os seguintes produtos sobre a germinação de esporos do patógeno: óleos essenciais de eucalipto, palma-rosa, cravo-da-índia, menta, limão, citronela e mil-folhas; extrato pirolenhoso de eucalipto e mentol cristalizado, em diferentes concentrações. Para os testes de campo foram selecionados quatro produtos, o óleo de citronela e de eucalipto, o extrato pirolenhoso, e o mentol. In vitro, todos os agentes mostraram-se promissores no controle do patógeno. Quando em condições in vivo, sob alta severidade da doença no ato da avaliação, os produtos testados foram capazes de reduzir a severidade da doença em comparação com a testemunha. O controle da doença com os agentes naturais variou de $38 \%$ (extrato pirolenhoso) a $61 \%$ (óleo essencial de eucalipto).
\end{abstract}

Palavras-chave: controle alternativo de doenças de plantas, óleos essenciais, Puccinia nakanishikii

\begin{abstract}
Rust control in leaves of lemongrass [Cymbopogon citratus (DC.) Stapf] by using natural products. Cymbopogon citratus (DC.) Stapf is a medicinal plant that belongs to the Poaceae family; it is perennial and important for the pharmaceutical and food industry due to the essential oil it produces. A limiting problem for commercial production is rust, a disease that has as etiological agent the fungus Puccinia nakanishikii Dietel. The present study aimed to evaluate the action of natural products on the disease control, in vitro and in vivo. For the in vitro tests, the following products were employed on the germination of the pathogen spores: essential oils from eucalyptus, palmarosa, clove, peppermint, lemon, citronella and yarrow, pyroligneous extract from eucalyptus, and crystallized menthol, at different concentrations. Four products were selected for the tests in the field: citronella and eucalyptus oil, pyroligneous extract and menthol. In vitro, all agents showed promising in controlling the pathogen. Under in vivo conditions and great severity of the disease at evaluation, the tested products were capable of reducing the disease severity when compared to the control. The disease control by the natural products varied from 38\% (pyroligneous extract) to $61 \%$ (eucalyptus essential oil).
\end{abstract}

Key words: alternative control of plant diseases, essential oils, Puccinia nakanishikii

\section{INTRODUÇÃO}

O capim limão [Cymbopogon citratus (DC.) Stapf] é uma gramínea perene, originária da Índia, conhecida popularmente como capim cidró, capim cidreira, cidrão, citronela de Java, capim-santo, erva cidreira (Castro \& Chemale, 1995; Martins et al., 2000). Apresenta odor característico de limão, sabor aromático e ardente e coloração verde-pálida (Gomes
\& Negrelle, 2003). Amplamente distribuído é empregado na medicina popular como calmante, espasmolítico e antimicrobiano (Lorenzi \& Matos, 2008). O óleo essencial da planta é usado industrialmente pelo segmento alimentício, cosmético, de perfumaria e na fabricação de inseticidas (Negrelle \& Gomes, 2007).

Recebido para publicação em 07/05/2009

Aceito para publicação em 20/04/2012

Rev. Bras. PI. Med., Botucatu, v.14, n.4, p.571-578, 2012. 
No Brasil, a produção comercial apresenta grande importância nos Estados do Sul e Sudeste, notadamente no Estado do Paraná, considerado o maior produtor de plantas medicinais no país (Gomes et al., 2007).

Em relação à produção de plantas medicinais, o controle de qualidade torna-se elemento importante, visando matérias-primas de qualidade, principalmente para o setor farmacêutico. Dentre os aspectos a serem analisados incluem-se os resíduos de pesticidas (WHO, 1998). Assim, práticas agrícolas apropriadas permitem melhorar a qualidade das matérias primas vegetais (WHO, 2003). No Brasil, não existe legislação específica para a questão de produção de plantas medicinais.

Aliado a este fato, o aumento da demanda por plantas medicinais perante a oferta insuficiente leva a queda da qualidade das matérias primas devido ao desconhecimento, por parte de produtores, de cuidados nas diversas etapas para a obtenção de matérias-primas (Zaroni et al., 2004).

Diante do aumento de demanda e de produtos de qualidade e da falta de legislação específica, um dos entraves para o cultivo de plantas medicinais são as doenças. Para plantas medicinais, assim como para todas as culturas comercias, a presença de doenças torna-se fator limitante e desafiador. No caso específico das plantas medicinais, devido ao desconhecimento de formas de controle, bem como pela falta de registro de produtos (Agrofit, 2011).

Buscando uma alternativa eficiente, visando driblar a falta de registro de produtos, juntamente com a necessidade de produtos de qualidade, o cultivo orgânico torna-se uma opção.

Apesar de ser uma planta medicinal empregada como insumos no controle de doenças de plantas (Stangarlin, 2007), no capim limão durante o cultivo a ferrugem das folhas é um sério problema. González et al. (2008) observaram incidência de 100\% e severidades variáveis de ferrugem causada por Puccinia sp. em áreas de cultivo de capim limão. Skaria et al. (2006) relatam a ferrugem como uma doença presente em cultivos da gramínea na Índia.

No Brasil o primeiro relato desta doença é recente, sendo feito no Estado do Paraná, no qual o patógeno relacionado foi Puccinia cymbopogonis Mass. e tem causado grandes danos a cultura (Vida et al., 2006). Contudo, em áreas do Estado de São Paulo relata-se outra espécie do gênero, Puccinia nakanishikii Dietel (Lorenzetti, 2009) a qual foi relatada como agente causal da ferrugem em plantações de capim-limão no Hawai e na Califórnia (Gardner, 1985; Koike, 1999). No Brasil, o primeiro relato do patógeno foi feito no Rio de Janeiro (Melo et al., 2008).

Nos Estados Unidos, além de algumas medidas recomendadas para o controle, um fungicida é recomendado, contudo sem estudos a respeito da eficiência (Nelson, 2008). No Brasil, ainda não há registros de formas de controle para essa doença. Conceição et al. (2008) e Lorenzetti et al. (2008b) relatam formas de controle alternativo in vitro para a doença, através da inibição da germinação de esporos do fungo com óleos essenciais e preparados homeopáticos. Assim, o presente trabalho objetivou testar produtos naturais no controle da ferrugem das folhas do capim-limão, em condições in vitro e in vivo.

\section{MATERIALE MÉTODO}

$O$ experimento in vitro foi conduzido nas dependências do Departamento de Produção Vegetal da Faculdade de Ciências Agronômicas, UNESP, Campus de Botucatu, no Laboratório de Patologia de Plantas do Setor de Defesa Fitossanitária.

O experimento in vivo foi realizado na Fazenda Experimental de São Manuel, a qual está situada a $22^{\circ} 44^{\prime}$ de latitude $S$ e $48^{\circ} 34^{\prime}$ ' de longitude $\mathrm{W}$ e $740 \mathrm{~m}$ de altitude. O clima é classificado como Cfa. O solo foi caracterizado como Latossolo Vermelho Amarelo, de textura arenosa.

\section{Testes in vitro para a inibição da germinação de esporos de $P$. nakanishikii \\ Foram utilizados os seguintes produtos} naturais na inibição da germinação de esporos de $P$. nakanishikii: óleos essenciais de eucalipto (Corymbia citriodora), palma-rosa (Cymbopogon martini), cravoda-índia (Syzigium aromaticum), menta (Mentha spp.), limão (Citrus limonum), citronela (Cymbopogon nardus) e mil folhas (Achillea millefolium) e mentol cristalizado comercial solubilizado nas concentrações de 100, 200, 300 e 400 ppm e extrato pirolenhoso de C. citriodora, nas concentrações de 10, 20, 30, 40 e $50 \mathrm{~g} \mathrm{~L}^{-1}$. Os testes em condições controladas foram realizados utilizando-se placas de Petri estéreis, contendo $10 \mathrm{~mL}$ de meio de cultura agar-água e os produtos naturais.

Todos os óleos essenciais foram obtidos através do processo de hidrodestilação, com aparelho do tipo Clevenger. O mentol cristalizado foi adquirido no comércio, e o extrato pirolenhoso foi cedido pela empresa AgTec, sediada no município de Dois Córregos, SP.

Os óleos foram misturados em agente surfactante, Tween 80 , para garantir a incorporação do óleo ao meio agar-água fundente, numa temperatura de $50^{\circ} \mathrm{C}$, em frascos esterilizados com agitação. Após este procedimento, o meio contendo óleo foi colocado nas placas de Petri, sendo mantidas até a completa solidificação em condições assépticas. Quantidades suficientes do mentol cristalizado foram solubilizadas em etanol $96 \%$, para a obtenção das 
concentrações empregadas; as soluções foram misturadas ao meio de cultura fundente em procedimento semelhante ao realizado para os óleos. O extrato pirolenhoso foi adicionado diretamente ao meio de cultura fundente da mesma maneira que os demais tratamentos.

Os tratamentos de controle negativo constaram de placas de Petri contendo apenas o meio de cultura ou o meio de cultura acrescido de Tween 80, conforme o caso. O controle positivo constou de um fungicida à base de mancozeb considerado padrão químico eficiente no combate de ferrugens, incluído ao meio de cultura na dose de $2 \mathrm{~g}$ $\mathrm{L}^{-1}$ recomendada pelo fabricante.

Para a avaliação da germinação foi elaborada uma suspensão de $1 \times 10^{5}$ esporos do patógeno por $\mathrm{mL}$. Estes esporos foram obtidos através de raspagem das pústulas presentes na face abaxial das folhas de plantas infectadas trazidas de área de cultivo, sendo os esporos transferidos para tubos tipo Eppendorf contendo água destilada estéril. Para a inoculação, foram utilizados $20 \mu \mathrm{L}$ da suspensão de esporos por repetição, colocadas sobre o meio de cultura com os produtos naturais para todos os tratamentos.

Após a inoculação, as placas permaneceram na ausência de luz, em temperatura de $23^{\circ} \mathrm{C}$ por 24 horas, em câmara de germinação. Foi utilizada a solução de azul de algodão mais lactofenol $(0,5 \mathrm{~mL})$ para interromper o desenvolvimento dos esporos. Para a avaliação foi realizada a contagem de 50 esporos em campo escolhido aleatoriamente na lâmina com aumento de 100 vezes, em microscópio de luz, para estimar a porcentagem de germinação dos esporos do patógeno. Foram considerados germinados os esporos que apresentavam tubo germinativo de tamanho superior ao diâmetro do esporo.

Adotou-se o delineamento inteiramente casualizado (DIC) constando de sete tratamentos e quatro repetições por tratamento. $\mathrm{Na}$ análise estatística os tratamentos que apresentavam todos os valores das repetições iguais a zero foram excluídos, os demais tratamentos tiveram os valores transformados para $\sqrt{\operatorname{arcsen}}$ visando a homogeneidade das variâncias. Após significância para $\mathrm{H}_{\mathrm{a}}$ em análise de variância aplicou-se o teste de Dunnet a $5 \%$ de probabilidade. Todas as etapas do estudo estatístico foram realizadas em sistema SAS (SAS Institute, 1999).

\section{Testes em campo para o controle de $P$. nakanishikii}

Os propágulos para o cultivo de Cymbopogon citratus foram obtidos do Horto de Plantas Medicinais e Tóxicas da Faculdade de Ciências Farmacêuticas, UNESP Campus de Araraquara - SP, aclimatados e repicados em uma área da Fazenda Experimental de São Manuel durante os meses de dezembro de 2007 a fevereiro de 2008.

Após o desenvolvimento das plantas, executou-se a divisão das touceiras, das quais foram retiradas mudas padronizadas com $20 \mathrm{~cm}$ de altura. Após avaliação das características de fertilidade do solo, não foi necessária a realização de calagem na área, que foi preparada em canteiros de $1,2 \mathrm{~m}$ de largura. $\mathrm{O}$ espaçamento utilizado foi de $0,5 \mathrm{~m}$ entre plantas e entre linhas.

A adubação de plantio constou de esterco curtido na quantidade de $30 \mathrm{t} \mathrm{ha}^{-1}$. A irrigação foi feita por aspersão segundo a necessidade da cultura. $O$ controle de plantas daninhas foi feito através de capina manual.

As parcelas experimentais foram representadas por trinta plantas, dispostas em três linhas, numa área total de $12 \mathrm{~m}^{2}$, considerando-se como parcela útil cinco plantas centrais. O delineamento estatístico experimental adotado foi o de blocos casualizados com quatro repetições.

A condução dos ensaios in vitro permitiu a seleção de quatro tipos de agentes naturais para serem empregados no ensaio de campo, o óleo essencial de citronela e de eucalipto; o mentol cristalizado e o extrato pirolenhoso.

Como controle positivo, da mesma forma que nos testes in vitro empregou-se um fungicida a base de mancozeb, indicado para o controle de fungos do gênero Puccinia na dose de $2 \mathrm{~g} \mathrm{~L}^{-1}$ e uma testemunha (controle negativo), com aplicação de água.

Nas condições de condução do experimento de campo, empregaram-se na primeira aplicação dos agentes as concentrações de 1000 ppm para os óleos essenciais e também para o mentol, e $25 \mathrm{~g} \mathrm{~L}^{-1} \mathrm{de}$ extrato pirolenhoso; todas testadas anteriormente em ensaios preliminares em casa de vegetação (dados não apresentados). Após a primeira avaliação, a concentração dos óleos essenciais foi diminuída para 750 ppm devido ao aparecimento de sintomas de fitotoxidez que não ocorreram anteriormente em condições de casa de vegetação.

Utilizou-se pulverizador manual de $5 \mathrm{~L}$ de capacidade para o preparo e aplicação das caldas na quantidade de $1000 \mathrm{~L} \mathrm{ha}^{-1}$, contendo espalhante adesivo siliconado na dose de $0,3 \mathrm{~mL} \mathrm{~L}^{-1}$. Entre as aplicações, para a limpeza do pulverizador foi utilizado etanol $96 \%$ e água contendo detergente neutro, num total de três lavagens sucessivas. Para o fungicida foi utilizado pulverizador exclusivo evitando contaminação entre os tratamentos. Foram realizadas aplicações semanais durante o período de 45 dias iniciando após a constatação do patógeno em todas as parcelas, através de infecção natural.

Após 30 dias do início das aplicações dos produtos para o controle da doença foi realizada a avaliação de duas folhas por planta útil (cinco no total), sendo considerada a terceira e a quinta folha do 
perfilho central da planta. Estas folhas foram submetidas a cópia digital através de scanner e a área lesionada quantificada com o auxílio do programa Diseased Area Meter (DAM), desenvolvido pelo Setor de Defesa Fitossanitária, da FCA -Unesp, em vias de registro de software.

Foi realizada colheita quinze dias após a avaliação e a última aplicação, visando à eliminação de folhas lesionadas, reproduzindo condições realizadas em cultivos comerciais. Quinze dias após o corte constataram-se os primeiros sintomas da doença, quando as plantas apresentavam $30 \mathrm{~cm}$ de altura. Reiniciaram-se as aplicações, que foram realizadas por mais trinta dias, semanalmente. Após esse período foi feita a mesma avaliação realizada anteriormente.

Com a finalidade de obter a estimativa de produção, quarenta e cinco dias após o primeiro corte foi realizado um segundo corte nas três plantas centrais de cada parcela, e as folhas foram secas em estufa com circulação de ar a $40^{\circ} \mathrm{C}$ até massa constante. Foi avaliada a massa da matéria seca das folhas dos tratamentos. Foi feita ainda avaliação da quantidade de óleo essencial produzido pelas plantas em cada tratamento, sendo os óleos obtidos através do processo de hidrodestilação, com aparelho do tipo Clevenger. Sessenta dias após o segundo corte, a terceira e a quinta folhas do perfilho central da planta foram retiradas e as pústulas de ferrugem raspadas para liberação dos urediniósporos. Os urediniósporos de cada tratamento foram colocados em uma superfície de papel branco uniforme com área conhecida. Foi obtida uma cópia digital através de câmara fotográfica em distância focal definida. Aárea ocupada por urediniósporos foi definida através da análise de imagens pelo software ImageJ (Abramoff et al., 2004).

Os valores obtidos para todas as variáveis foram submetidos à análise de variância e as médias foram comparadas pelo teste de Tukey a $5 \%$ de probabilidade utilizando o programa SAS (Sas Institute, 1999).

\section{RESULTADO E DISCUSSÃO}

\section{Inibição da germinação de urediniósporos de $P$. nakanishiki in vitro}

Todos os produtos empregados, óleos essenciais, mentol e extrato pirolenhoso, mostraramse eficientes na inibição da germinação dos urediniósporos da ferrugem. Contudo, os tratamentos com os óleos essenciais de eucalipto $(200,300 \mathrm{e}$ 400 ppm), limão (300 ppm) e mil-folhas (300 e 400 $\mathrm{ppm}$ ) e o extrato pirolenhoso (40 e $50 \mathrm{~g} \mathrm{~L}^{-1}$ ) inibiram em $100 \%$ a germinação dos urediniósporos do patógeno. Todos os demais tratamentos, incluindo as diferentes concentrações, demonstraram controle eficiente em relação à testemunha. Em relação ao padrão químico, todos os tratamentos, apresentaram eficiência, demonstrando potencial para utilização em campo (Tabela 1).

O surfactante Tween 80 , usado para os óleos, não interferiu na germinação dos esporos do fungo, obtendo valores de germinação de esporos do patógeno comparáveis aos da testemunha. Assim, este produto pode ser empregado para a emulsificação dos óleos de maneira eficiente em experimentos in vitro.

Outros trabalhos demonstram resultados positivos dos mesmos óleos essenciais. Bonaldo et al. (2007), empregando óleos essenciais e extratos de eucalipto Corymbia citriodora, obtiveram resultados positivos na inibição do desenvolvimento de fungos fitopatogênicos e também sobre a germinação de conídios de Colletotrichum sublineolum. Com a mesma espécie, Abreu (2006) também obteve inibição total do desenvolvimento de Alternaria solani, com concentrações de $2000 \mu \mathrm{L} \mathrm{L}^{-1} \mathrm{em}$ testes in vitro. Para ferrugem da soja, o óleo de eucalipto (concentração de $1 \%$ ), inibiu $100 \%$ da germinação destes esporos (Médice et al., 2007).

Mccalley \& Torres-Grifol (1992), citados por Abreu (2006) indicam que o óleo de limão é pouco eficiente na inibição de micro-organismos, contudo, apresentam especificidade para certos fungos ou bactérias. Neste caso, para esporos deste patógeno, foi eficiente.

Quanto à espécie mil-folhas, Fiori et al. (2000) demonstram o efeito de extratos de folhas e do óleo essencial desta espécie na redução da germinação de esporos de Dydimela bryoniae, embora o efeito no crescimento micelial do fungo não ser tão pronunciado.

As concentrações dos óleos essenciais empregados não demonstram relação linear quanto à inibição da germinação, o que pode ser observado para o óleo de limão, por exemplo, no qual a concentração de $0,03 \%$ apresentou melhores resultados que $0,04 \%$. Tendência semelhante foi observada por Abreu (2006) para o controle in vitro de Alternaria solani. Apesar do emprego de produtos e técnicas para a dispersão dos óleos no meio, a heterogeneidade dos produtos no meio de cultura pode explicar este fato, visto que o campo óptico escolhido para avaliação é feito ao acaso.

Em relação ao extrato pirolenhoso, as duas concentrações mais altas propiciaram 100\% de inibição na germinação dos esporos do patógeno. As demais concentrações mostraramse altamente eficientes. Há poucos relatos do emprego do extrato pirolenhoso para controle de patógenos, um exemplo é para o controle de patógenos de solo (Numata et al.,1994). Contudo,

Rev. Bras. PI. Med., Botucatu, v.14, n.4, p.571-578, 2012. 
TABELA 1. Porcentagem de germinação de esporos de Puccinia nakanishikii submetidos a diferentes agentes de controle e concentrações de princípios ativos. FCA/ Unesp, Botucatu - SP, 2008.

\begin{tabular}{|c|c|c|c|c|c|}
\hline \multirow[t]{2}{*}{ Agente } & \multicolumn{4}{|c|}{ Concentrações (ppm) } & \multirow[b]{2}{*}{400} \\
\hline & 100 & 200 & 300 & & \\
\hline Eucalipto & $1,00^{\mathrm{b}}$ & $0,00^{b}$ & $0,00^{b}$ & & $0,00^{b}$ \\
\hline Cravo-da-índia & $1,00^{b}$ & $2,50^{\mathrm{b}}$ & $2,50^{b}$ & & $7,00^{\mathrm{b}}$ \\
\hline Menta & $5,00^{b}$ & $7,00^{b}$ & $6,50^{b}$ & & $4,50^{\mathrm{b}}$ \\
\hline Palma-rosa & $4,50^{b}$ & $0,50^{b}$ & $7,00^{b}$ & & $5,00^{b}$ \\
\hline Limão & $2,50^{b}$ & $3,00^{b}$ & $0,00^{b}$ & & $3,00^{b}$ \\
\hline Mil-folhas & $3,00^{b}$ & $1,00^{b}$ & $0,00^{b}$ & & $0,00^{b}$ \\
\hline Citronela & $0,50^{b}$ & $0,50^{b}$ & $0,50^{b}$ & & $0,00^{b}$ \\
\hline Mentol & $9,50^{\mathrm{b}}$ & $7,50^{b}$ & $4,00^{b}$ & & $1,00^{b}$ \\
\hline \multicolumn{6}{|c|}{ Concentrações $\left(\mathrm{g} \mathrm{L}^{-1}\right)$} \\
\hline & 10 & 20 & 30 & 40 & 50 \\
\hline Extrato Pirolenhoso & $4,00^{b}$ & $0,50^{\mathrm{b}}$ & $2,00^{b}$ & $0,00^{b}$ & $0,00^{b}$ \\
\hline Fungicida (Mancozeb) & & & $2,50^{b}$ & & \\
\hline Tween 80 & & & 82,50 a & & \\
\hline Testemunha & & & 88,00 a & & \\
\hline CV \% & & & 38,41 & & \\
\hline
\end{tabular}

Médias seguidas de letras minúsculas distintas diferem da testemunha pelo teste de Dunnet $(p>0,05)$, dados transformados em arc seno $\sqrt{ }$.

o uso como fertilizante orgânico é extenso (Tsuzuki et al., 2000).

Para o mentol, todas as concentrações utilizadas de princípios ativos foram eficientes em relação à testemunha. Como o mentol não pode ser solubilizado em água necessita-se de formas diferenciadas de dissolução a fim de aprimorar o uso deste composto.

Tanto para os óleos essenciais quanto para o mentol, formulações eficientes são necessárias. Inovações quanto a formulações são alguns dos desafios recentes para obtenção de produtos para uso em agricultura, principalmente em relação ao controle biológico. Um dos maiores inconvenientes, no caso de óleos essenciais na agricultura, é a instabilidade química na presença do ar, luz, outras misturas e temperaturas altas, levando a rápida evaporação e degradação de componentes (Pillmoor, et al., 1993). Encapsulamento do óleo essencial em nanopartículas mostra-se como opção para elaboração de formulações (Lai et al., 2006).

Com os resultados promissores apresentados por todos os produtos naturais, principalmente pelos óleos essenciais, optou-se por aqueles de mais fácil obtenção, disponibilidade de aquisição, ou seja, de maior viabilidade econômica.
Testes em campo para a inibição da germinação de esporos de $P$. nakanishikii

Para a primeira etapa do experimento, as aplicações dos produtos resultaram na redução da esporulação do patógeno, observável através da comparação da testemunha com os tratamentos através de escala diagramática (Lorenzetti et al., 2008a).

Quanto à incidência, todas as plantas do experimento apresentavam-se afetadas pelo patógeno em todas as avaliações. Na avaliação da severidade realizada após trinta dias da aplicação dos produtos através de análise de imagens digitais, todos os tratamentos, com exceção do extrato pirolenhoso, mostraram controle em relação à testemunha (Tabela 2 ).

Após a primeira colheita realizada seguida desta avaliação, as folhas senescentes e restos culturais foram eliminados da área. Quinze dias depois do corte os primeiros sintomas da doença reapareceram nas folhas novas. Com trinta dias do corte, as plantas estavam com $50 \mathrm{~cm}$ de altura. Aos quarenta e cinco dias após o corte, na segunda avaliação da severidade, as plantas apresentavam 80 $\mathrm{cm}$ de altura. Os valores de severidade foram inferiores para a segunda avaliação em todos os tratamentos. 
TABELA 2. Produtos naturais no controle da ferrugem do capim-limão em condições de campo. FCA/ Unesp, Botucatu - SP, 2008.

\begin{tabular}{|c|c|c|}
\hline \multirow{2}{*}{ Produto } & $\begin{array}{c}\% \text { de área foliar } \\
\text { infectada }\end{array}$ & $\begin{array}{c}\% \text { de área foliar } \\
\text { infectada }\end{array}$ \\
\hline & 1a Avaliação & 2a Avaliação \\
\hline Testemunha & $36,119 \mathrm{a}^{*}$ & 2,508 a1 \\
\hline Fungicida & 19,550 b & 0,264 b \\
\hline Extrato pirolenhoso & $22,295 a b$ & $1,396 a b$ \\
\hline Óleo essencial de Citronela & 18,991 b & $1,019 a b$ \\
\hline Mentol & $16,713^{b}$ & $1,719 a b$ \\
\hline Óleo essencial de Eucalipto & 13,887 b & $0,962^{\mathrm{ab}}$ \\
\hline CV \% & 33,844 & 37,352 \\
\hline
\end{tabular}

* Médias seguidas de letras minúsculas distintas na coluna diferem entre si pelo teste de Tukey $(p>0,05) .{ }^{1}$ Dados transformados para arc sen $\sqrt{\text { na segunda avaliação }}$

Para a segunda avaliação o tratamento com o fungicida mostrou-se superior à testemunha, controlando a doença. Os demais tratamentos não diferiram, porém apresentaram tendência a redução da área infectada.

A realização da colheita com a eliminação de restos culturais mostra-se eficiente para o controle da doença, o que pode ser observado nos valores inferiores apresentados na segunda avaliação. Intervalos maiores entre colheitas podem prejudicar a qualidade do produto devido ao decréscimo linear do acúmulo de matéria seca (May et al., 2008). Além disso, com o aumento da severidade da doença, a aparência da matéria prima será prejudicada pelo aumento dos sintomas da doença. O intervalo de 40 dias além de favorável para boa acumulação de matéria seca mostra-se eficiente para o controle da ferrugem em campo.

Aliado ao corte, a adoção de pulverizações auxilia no manejo fitossanitário da cultura. Quanto aos tipos de agentes de controle empregados, os óleos essenciais demonstram boa eficiência. Para o mentol são necessários ensaios de formulação, adaptando um elemento no qual fosse adequadamente dissolvido o produto comercial. $\mathrm{O}$ extrato pirolenhoso necessita de adequações quanto à dose, necessitando serem testadas doses maiores, além disso, aspectos relacionados à nutrição podem ser observados, visto que apresenta uso como fertilizante foliar. A aplicação de fungicidas mostra-se eficiente, podendo ser adotada em cultivos convencionais, desde que o produto seja registrado futuramente para tal finalidade.

Com o aumento da severidade da ferrugem há redução da quantidade de óleo essencial, em severidades superiores a $8 \%$ a produção de óleo cai em relação à produtividade da espécie (Lorenzetti, 2009). Para o ensaio, não houve diferenças consideráveis entre produtividade e quantidade de óleo nos tratamentos avaliados ao fim da segunda avaliação, devido a baixa severidade encontrada em todas as plantas avaliadas.

A produção para todos os tratamentos em toda área foi estimada em $4,260 \mathrm{t} \mathrm{ha}^{-1}$ de massa seca ao final da segunda avaliação. A produção média de óleo para os tratamentos foi de $1,80 \%$, o recomendado segundo a Farmacopéia (2003) é de $0,5 \%$. Não houve diferenças significativas para as duas características avaliada sob ação dos tratamentos. Contudo, na análise realizada através da avaliação de imagens da área ocupada por urediniósporos de ferrugem (Figura 1) todos os produtos naturais aplicados mostraram redução da quantidade de urediniósporos retirados da folha, demonstrando potencial para diminuir epidemias da doença.

Segundo o desenvolvimento da espécie, esta apresenta senescência natural juntamente com o surgimento de folhas mais jovens, o que pode ser observado no material vegetal seco (Gomes \& Negrelle, 2003). A presença da ferrugem prejudica a qualidade do material vegetal seco, tanto folhas novas quanto folhas senescentes, devido à presença de pústulas de ferrugem.

Muitos são os trabalhos com controle in vitro. Contudo, ainda são poucos os resultados que podem ser aplicáveis em campo, principalmente com óleos essenciais. Para ensaios em campo com tomate, Abreu (2006) obteve controle da pinta-preta do tomateiro, Alternaria solani, com a utilização de óleos essenciais de cravo, eucalipto e de capim limão. Por outro lado, Casa (2008) testando produtos para controle fitossanitário, não observou controle eficiente 


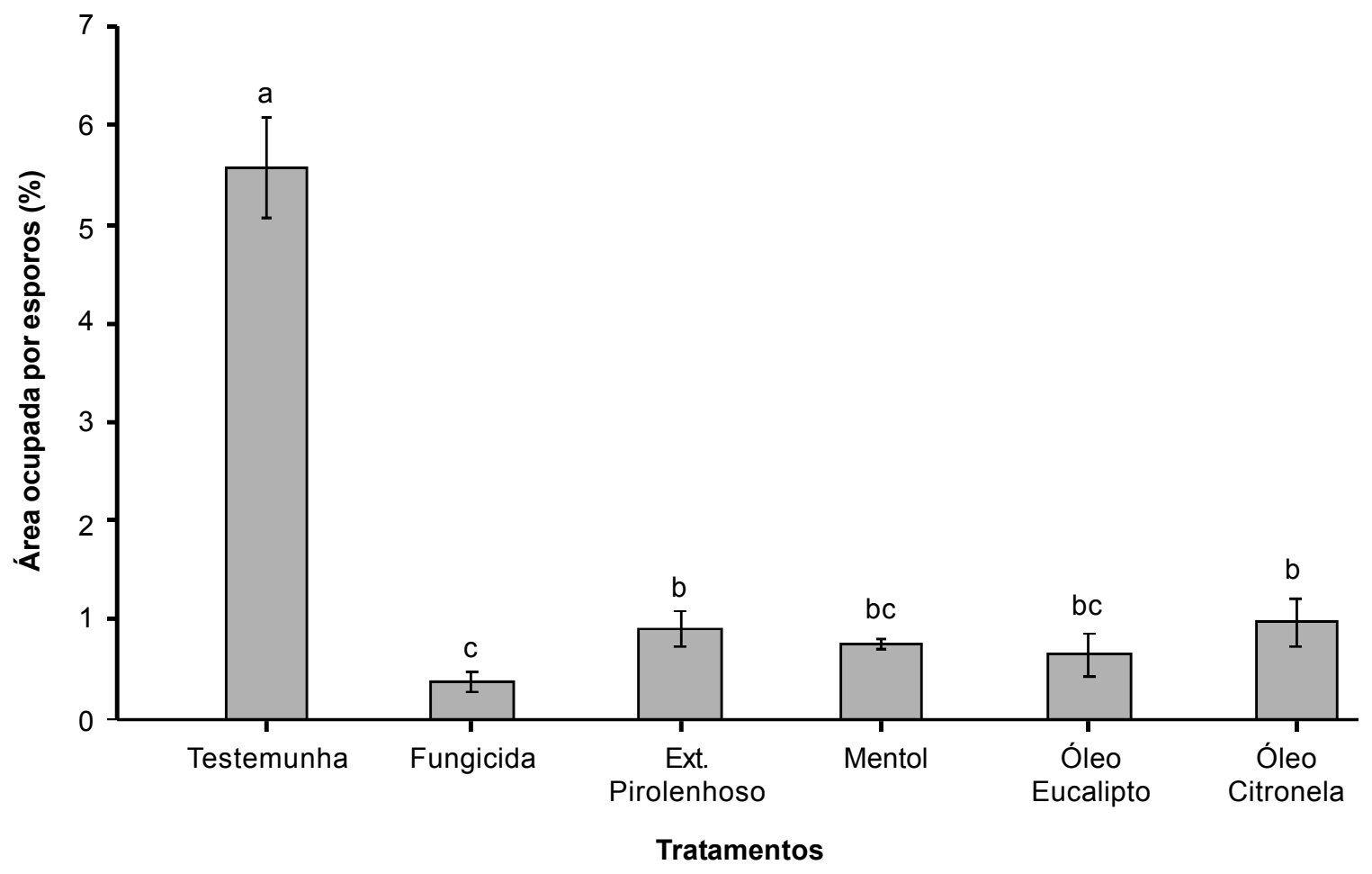

FIGURA 1. Área ocupada por uredinia de Puccinia nakanishikii sob ação de produtos naturais em condições de campo. Colunas com letras minúsculas distintas diferem entre si pelo teste de Tukey $(p>0,05)$. FCA/ Unesp, Botucatu - SP, 2008.

com o emprego de óleos essenciais. Com estes resultados, nota-se que a eficiência de tratamentos com óleos essenciais está relacionada diretamente com as condições ambientais e as características do patossistema envolvido.

São raros os experimentos com doenças em plantas medicinais. Metodologias ainda necessitam serem adaptadas para que se torne mais eficiente a forma de avaliação destas enfermidades nestes patossistemas. Apesar do grande crescimento do mercado de plantas medicinais, não há estudos específicos e conclusivos a respeito de doenças que acometem este tipo de cultivo, nem de produtos que podem ser aplicados sem interferirem na qualidade. Dentre as espécies medicinais, apenas para espécies de Mentha tais aspectos já são mais claros, como a existência de escala diagramática (Deschamps et al., 2008) e ensaios de controle (Edwards \& Bienveneu, 2000; Vaverková et al., 2009).

Óleos essenciais de eucalipto e citronela e mentol mostram-se como boas alternativas para o controle da doença. $O$ extrato pirolenhoso também se apresenta como um produto promissor, devendo ser ainda avaliada a viabilidade de emprego como fertilizante orgânico.

\section{REFERÊNCIA}

ABRAMOFF, M.D.; MAGELHAES, P.J.; RAM, S.J. Image processing with ImageJ. Biophotonics International, v.11, p.36-42, 2004.

ABREU, C.L.M. Controle de Alternaria solani em tomateiro (Lycopersicon esculentum) com óleos essenciais. 2006, 71p. Tese (Doutorado em Agronomia Horticultura) - Faculdade Ciências Agronômicas, Universidade Estadual Paulista, Botucatu.

AGROFIT - Ministéria da Agricultura Pecurária e Abastecimento do Brasil. Disponível em: <http:// www.agricultura.gov.br/portal/page/portal//nternet-MAPA/ pagina-inicial/servicos-e-sistemas/sistemas/agrofit>. Acesso em: 20 mai. 2011.

BONALDO, S.M. et al. Contribution for the study of antifungal and phytoalexins elicitors in sorghum and soybean activities by eucalyptus (Eucalyptus citriodora). Summa Phytopathologica, v.33, n.4, p.383-7, 2007.

CASA, J. Controle Fitossanitário no cultivo do tomateiro nos sistemas orgânico e biodinâmico de produção. 2008, 81p. Tese (Doutorado em Agronomia - Horticultura) Faculdade de Ciências Agronômicas, Universidade Estadual Paulista, Botucatu.

CASTRO, L.O.; CHEMALE, V.M. Plantas medicinais, condimentares e aromáticas. Guaiba: Agropecuária, 1995. 196p.

CONCEIÇÃO, D.M. et al. Controle de Puccinia cymbopogonis in vitro com óleos essenciais. In: CONGRESSO PAULISTA DE FITOPATOLOGIA, 31., 2008. Campinas. Summa Phytopathologica... 
Botucatu, 2008, p.13

DESCHAMPS, C. et al. Escala diagramática para avaliação da severidade da ferrugem de Mentha arvensis L. Revista Brasileira de Plantas Medicinais, v.10, n.1, p.82-7, 2008.

EDWARDS, J.; BIENVENU, F. Evaluation of selected fungicides to control mint rust on Scotch spearmint. Crop Protection, v.19, p.195-9, 2000.

Farmacopéia Brasileira. São Paulo: Atheneu, 2003. 548p.

FIORI, A.C.G. et al. Antifungical activity of leaf extracts and essential oils of some medicinal plants against Dydimella bryoniae. Journal of Phytopathology, v.148, n.7/8, p.483-7, 2000.

GARDNER, D.E. Lemongrass rust caused by Puccinia nakanishikii in Hawaii. Plant Disease, v.69, n.12, p.1100, 1985.

GOMES, E.C.; NEGRELLE, E.C.; DONI FILHO, L. Caracterização da produção de capim-limão no Estado do Paraná. Scientia Agraria, v.8, n.4, p.385-90, 2007.

GOMES, E.C.; NEGRELLE, R.R.B. Cymbopogon citratus (DC.) Stapf: aspectos botânicos e ecológicos. Visão Acadêmica, v.4, n.2, p.137-44, 2003.

GONZALEZ, J.C.A. et al. Evaluación de variables agronómicas en el cultivo de limonaria (Cymbopogon citratus Stapf) para la producción de aceite esencial. Interciência, v.33, n.9, p.693-9, 2008.

KOIKE, S.T. Rust disease on lemongrass in California. Plant Disease, v.83, n.6, p.304, 1999.

LAI, F. et al. Artemisia arborescens L. essential oil-loaded solid lipid nanoparticles for potential agricultural application: preparation and characterization. American Association of Pharmaceutical Scientists PharmSciTech, v.7, n.1, p.E1-9, 2006.

LORENZETTI, E.R. et al. Escala diagramática para determinação de área foliar lesionada para a ferrugem do capim-limão. In: CONGRESSO BRASILEIRO DE FITOPATOLOGIA , 41., 2008, Belo Horizonte. Tropical Plant Pathology, v.33, supl., p.304, 2008 a.

LORENZETTI, E.R. et al. Controle de Puccinia cymbopogonis in vitro com emprego de preparados homeopáticos, In: CONGRESSO PAULISTA DE FITOPATOLOGIA, 31., 2008. Campinas. Summa Phytopathologica, p.44-5, 2008b.

LORENZETTI, E.R. Interação patógeno: hospedeiro no patossistema capim limão - ferrugem das folhas e avaliação de ingredientes ativos naturais no controle da doença. 2009, 78p. Dissertação (Mestrado em Agronomia - Horticultura) - Faculdade de Ciências Agronômicas, Universidade Estadual Paulista, Botucatu. LORENZI, H.; MATOS, F.J.A. Plantas medicinais no Brasil: nativas e exóticas cultivadas. Nova Odessa: Plantarum, 2008, 544p.

MARTINS, E.R. et al. Plantas medicinais. Editora da UFV: Viçosa, 2000, 220p.
MAY, A. et al. Influência do intervalo entre cortes sobre a produção de biomassa de duas espécies de capim limão. Horticultura Brasileira, v.26, n.3, p.379-82, 2008. MEDICE, R. et al. Óleos essenciais no controle da ferrugem asiática da soja Phakopsora pachyrhizi Syd. \& P. Syd. Ciência e Agrotecnologia, v.31, n.1, p.83-90, 2007.

MELO, M.P. et al. Puccinia nakanishikii, nova ocorrência de ferrugem em capim-limão (Cymbopogon citratus) no Brasil, In: CONGRESSO BRASILEIRO DE FITOPATOLOGIA, 41., 2008, Belo Horizonte. Tropical Plant Pathology, v.33, supl., 2008, p.241.

NEGRELLE, R.R.B.; GOMES, E.C. Cymbopogon citratus (DC.) Stapf: chemical composition and biological activities. Revista Brasileira de Plantas Medicinais, v.9, n.1, p.80-92, 2007.

NELSON, S. Rust of lemongrass. Plant Disease, v.57, 2008, 5p. Disponível em: <http://www.ctahr.hawaii.edu/ oc/freepubs/pdf/PD-57.pdf>. Acesso em: 15 set. 2011. NUMATA, K.; OGAWA, T.; TANAKA, K. Effects of pyroligneous acid (wood vinegar) on the several soilborne diseases. Proceedings of the Kanto Tosan Plant Protectio Society, v.5, n.41, p.107-10, 1994.

PILLMOOR, J.B.; WRIGHT, K.; TERRY, A.S. Natural products as a source of agrochemicals and leads for chemical synthesis. Pesticide Science, v.39, p.131-40, 1993.

SAS INSTITUTE. SAS/STAT: user's guide. version 6.12. Cary, 1999, 842p.

SKARIA, B.P. et al. Lemongrass. In: PETER, K.V. Handbook of herbs and spices. Cornwall: CRC Press, v.3, 2006, p.400-16.

STANGARLIN, J.R. Uso de extratos e óleos essenciais no controle de doenças de plantas. Fitopatologia Brasileira, v.32, p.s94-6, 2007.

TSUZUKI, E.; MORIMITSU, T.; MATSUI, T. Effect of chemical compounds in pyroligneous acid on root growth in rice plant. Japan Journal Crop Science, v.66, n.4, p.156, 2000.

VAVERKOVÁ, S.; MISTRÍKOVÁ, I.; HOLLÁ, M. Qualitative properties of Mentha x piperita (L.) after application of the fungicide Hattrick DP-50. Plant, Soil and Enviroment, v.55, n.10, p.454-9, 2009.

VIDA, J.B.; CARVALHO JUNIOR, A.A.; VERZIGNASSI, J.R. Primeira ocorrência de ferrugem em capim-limão causada por Puccinia cymbopogonis no Brasil. Summa Phytopathologica, v.32, n.1, p.89-91, 2006.

ZARONI, M. et al. Qualidade microbiológica das plantas medicinais produzidas no Estado do Paraná. Revista Brasileira Farmacognosia, v.14, n.1, p.29-39, 2004. WHO - WORLD HEALTH ORGANIZATION. Quality control methods for medicinal plant materials. Geneva, 1998, $115 p$.

WHO - WORLD HEALTH ORGANIZATION. Guidelines on good agricultural and collection practices (GACP). Geneva, 2003, 72p. 